\title{
Resistência de Cultivares de Batata-Doce a Meloidogyne incognita*
}

\author{
Maria J. A. Wanderley**1 \& Jaime M. Santos ${ }^{2}$ \\ ${ }^{1}$ Departamento de Agropecuária, Centro de Formação de Tecnólogos, Universidade Federal da Paraíba, CEP 58220-000, \\ Bananeiras, PB, e-mail: mjwander@zipmail.com.br; ${ }^{2}$ Departamento de Fitossanidade, Faculdade de Ciências Agrárias e \\ Veterinárias, Universidade Estadual Paulista, Via de Acesso Prof. Paulo Donato Castellane s/n, CEP 14884-900, Jaboticabal, \\ SP, e-mail jmsantos@fcav.unesp.br
}

(Aceito para publicação em 13/02/2004)

Autor para correspondência: Maria José Araújo Wanderley

WANDERLEY, M.J.A. \& SANTOS, J.M. Resistência de cultivares de batata-doce a Meloidogyne incognita. Fitopatologia Brasileira 29:437440. 2004.

\section{RESUMO}

O presente trabalho teve o objetivo de estudar a resistência em 35 cultivares de batata-doce (Ipomoea batatas) a Meloidogyne incognita, bem como documentar alterações anatômicas em tecidos de raízes de cultivares infetadas. As plantas foram inoculadas em vasos com 3.000 ovos e juvenis de segundo estádio do nematóide e avaliadas aos 90 dias após com base no fator de reprodução (FR).
Entre as 35 cultivares 15 foram consideradas resistentes. Alterações anatômicas nas raízes de cultivares suscetíveis são ilustradas, observando-se bloqueio de vasos do xilema e supressão de tecidos vasculares.

Palavras-chave adicionais: Ipomoea batatas, nematóides de galhas, fator de reprodução, alterações anatômicas em raízes.

\section{ABSTRACT}

Resistance of sweet potato cultivars to Meloidogyne incognita

The objectives of this study were to evaluate the resistance of 35 sweet potato (Ipomoea batatas) cultivars to Meloidogyne incognita and illustrating anatomical changes in tissue of infected plants. The plants were inoculated with 3,000 eggs and juveniles of
M. incognita and evaluated at 90 days after inoculation based on the reproduction factor of the nematode (RF). Among the 35 cultivars tested, 15 of them were considered resistant. Anatomical changes in sweet potato roots are illustrated, showing interruption of xylem vessels and progressive suppression of vascular tissues.
A batata-doce [Ipomoea batatas (L.) Lam.] é uma das hortaliças que possui elevado teor nutritivo, devido a alta concentração de carboidratos, sais minerais, açúcares e vitaminas A, C e as do complexo B (Gandin et al., 1988). É cultivada principalmente em pequenas áreas, desempenhando maior importância para populações de baixa renda. O cultivo é em sistema de consórcio utilizando-se, quase sempre, mãode-obra familiar (Silva, 1991). A batata-doce é suscetível aos nematóides Rotylenchulus reniformis Linford \& Oliveira, Pratylenchus spp., Ditylenchus destructor Thorne (Jatala \& Bridge, 1990) e aos nematóides das galhas Meloidogyne spp. (Huang, et al., 1986). Neste caso, o parasitismo se dá, principalmente, por M. incognita Kofoid e White, Chitwood e M. javanica Treub, Chitwood, (Bridge \& Page, 1984). Meloidogyne incognita é a espécie mais importante para a cultura (Jatala \& Bridge, 1990), uma vez que o seu ataque além de determinar redução na produção, pode também causar rachaduras nos tubérculos, depreciando e inutilizando o produto para o comércio (Lordello, 1984).

Vários métodos podem ser utilizados no manejo de populações dos nematóides da batata-doce, sendo o uso de variedades resistentes uma das principais práticas dos

\footnotetext{
* Parte da Tese de Doutorado do primeiro autor apresentada à Universidade Estadual Paulista, Campus de Jaboticabal. (2003).

***Bolsista da CAPES
}

programas integrados (Taylor \& Sasser, 1978). Trabalhos com resistência de cultivares de batata-doce a nematóides têm sido desenvolvidos nas últimas décadas no Brasil (Huang et al., 1986; Maluf et al., 1996; Peixoto et. al., 1998). Entretanto, uma grande diversidade de cultivares ainda necessita ser avaliada. Assim, o presente trabalho teve como objetivo estudar o comportamento de 35 novas cultivares de batata-doce em relação ao parasitismo de $M$. incognita, bem como documentar alterações anatômicas em tecidos de raízes das cultivares infetadas.

Para a execução da pesquisa, uma coleção de cultivares de batata-doce foi instalada em área experimental do Departamento de Fitossanidade da Faculdade de Ciências Agrárias e Veterinárias (FCAV) da Universidade Estadual Paulista, Campus de Jaboticabal (UNESP). As cultivares foram provenientes da coleção mantida pela Universidade Federal Rural de Pernambuco, registradas como 'Beterraba', 'Bom Nome', 'Branca', 'Broca Roxa', 'Caboatã', 'CNPH-001', 'CNPH-004', 'CNPH-10', 'Cooperativa', 'CR-06', 'CR-42', 'CR-71', 'Fininha', 'J-06', 'Japonesa', 'Mineira', 'Nicão', 'Rainha Branca', 'Rama Fina', 'Roxa de Bonito', 'Siciliana', 'TR-02' e 'UFPRE', de áreas de produtores do município de Bananeiras, Paraíba 'Balão Roxo', 'Barba de Boi', 'Batateira', 'Brejeira', 'CO-Branca', 'Granfina' e 'Manteiguinha', e de produtores do município São José de Espinharas, PB 'Brejo 
do Cruz', 'Grossa da Paz', 'Lagartixa', 'Roxa da Paz', e 'São Jorge'. No início da pesquisa, mudas foram coletadas da coleção e transportadas em caixas de isopor para a casa de vegetação do Setor de Agricultura, do Centro de Formação de Tecnólogos da Universidade Federal da Paraíba, em Bananeiras, onde foram colocadas em frascos de vidro, contendo água pura para enraizarem, permanecendo por três semanas, com troca da água a cada dois dias. Após o enraizamento, cinco mudas de cada cultivar foram plantadas individualmente, em vasos plásticos, com capacidade para 51 , contendo uma mistura de solo, areia e esterco bovino curtido, na proporção de 1:2:1. Esse substrato foi previamente tratado por solarização (Katan, 1981). Cada muda foi inoculada, 30 dias após o plantio, com $10 \mathrm{ml}$ de uma suspensão, contendo cerca de 3.000 ovos e juvenis de M. incognita por vaso (Huang et al., 1986). A população de $M$. incognita utilizada como inóculo foi proveniente de plantas de jiló Solanum gilo Raddi, sendo previamente identificada com base no exame da configuração perineal, segundo Taylor \& Netscher (1974) e na morfologia da região labial de machos (Eisenback, 1985), com confirmação final pela determinação do fenótipo isoenzimático para esterase (Esbenshade \& Triantaphyllou, 1990). O inóculo foi preparado conforme metodologia descrita por Coolen \& D’Herde (1972). Os tratamentos constituídos pelas 35 cultivares foram distribuídos inteiramente ao acaso, com cinco repetições. A avaliação da resistência das cultivares foi realizada com base no fator de reprodução (FR) segundo Cook \& Evans (1987), 90 dias após a inoculação. Foram consideradas cultivares resistentes aquelas que exibiram valor do $F R<1$ e suscetíveis as com FR $>1$. Preparações histológicas de tecidos de raízes de batata-doce sadias e com galhas foram efetuadas segundo Daykin \& Hussey (1985) objetivando-se documentar alterações anatômicas em raízes de plantas suscetíveis.

As cultivares de batata-doce classificadas como resistentes tiveram o FR variando de 0,05 a 0,98 (Tabela 1).
'Rama Fina' foi a cultivar que apresentou o maior nível de resistência. Dentre as cultivares resistentes, 12 foram procedentes da coleção de batata-doce da UFRPE, enquanto que dentre as cultivadas do Estado da Paraíba, apenas as cultivares Batateira, São Jorge e Grossa da Paz foram resistentes. As demais cultivares apresentaram FR entre 1,16 a 21,34 sendo classificadas como suscetíveis. 'Brejo do Cruz' foi considerada a mais suscetível. Huang et al. (1986) avaliaram resistência em 123 clones de batata-doce da coleção do CNPH/EMBRAPA a $M$. incognita e $M$. javanica e concluíram que existiam muitas fontes de resistência a ambos os nematóides na mencionada coleção. Maluf et al. (1996) avaliaram a resistência de outros 226 clones de batata-doce aos nematóides de galha M. javanica e M. incognita. A maioria dos clones foram resistentes a $M$. javanica e poucos a $M$. incognita. Peixoto et al. (1998) também avaliaram resistência em outras 70 cultivares de batata-doce a $M$. incognita e $M$. javanica e encontraram resistência a ambos os nematóides em 21. Nenhuma das cultivares incluídas no presente estudo havia sido avaliada anteriormente.

Os caracteres morfológicos e bioquímico mais marcantes que dão suporte à identificação de $M$. incognita utilizada na presente pesquisa estão ilustrados na Figura 1 AC. A região perineal (Figura $1 \mathrm{~A}$ ) e a região labial dos machos (Figura 1 B) exibem caracteres morfológicos muito característicos desta espécie.

O fenótipo isoenzimático de esterase observado para M. incognita (Figura 1 C), é constituído por uma única banda na altura da banda de menor mobilidade do fenótipo de $M$. javanica (Esbenshade \& Triantaphyllou, 1990). Meloidogyne incognita causa consideráveis alterações anatômicas em raízes de batata-doce suscetíveis, entre as quais bloqueio, compressão e interrupção de vasos do xilema. A Figura $1 \mathrm{D}$ representa uma seção transversal de uma raiz sadia, utilizada como comparativo das alterações anatômicas causadas pelo nematóide. Face à afinidade da lignina pela safranina $\mathrm{O}$,

TABELA 1 - Cultivares de batata-doce (Ipomea batatas) resistentes a Meloidogyne incognita, avaliadas pelo Fator de Reprodução

\begin{tabular}{llcc}
\hline \hline Cultivar & Procedência & Fator de Reprodução (FR) & Classificação \\
\hline Roxa de Bonito & UFRPE - Recife, PE & 0,98 & $\mathrm{R}^{1}$ \\
Beterraba & UFRPE - Recife, PE & 0,87 & $\mathrm{R}$ \\
UFRPE & UFRPE - Recife, PE & 0,78 & $\mathrm{R}$ \\
CNPH-004 & UFRPE - Recife, PE & 0,74 & $\mathrm{R}$ \\
Caboatã & UFRPE - Recife, PE & 0,71 & $\mathrm{R}$ \\
Cooperativa & UFRPE - Recife, PE & 0,65 & $\mathrm{R}$ \\
TR-02 & UFRPE - Recife, PE & 0,62 & $\mathrm{R}$ \\
Siciliana & UFRPE - Recife, PE & 0,58 & $\mathrm{R}$ \\
CNPH-10 & UFRPE - Recife, PE & 0,55 & $\mathrm{R}$ \\
CR-06 & UFRPE - Recife, PE & 0,53 & $\mathrm{R}$ \\
Batateira & Bananeiras, PB & 0,41 & $\mathrm{R}$ \\
São Jorge & São José de Espinharas, PB & 0,38 & $\mathrm{R}$ \\
Grossa da paz & São José de Espinharas, PB & 0,33 & $\mathrm{R}$ \\
Branca & UFRPE - Recife, PE & 0,12 & $\mathrm{R}$ \\
Rama fina & UFRPE - Recife, PE & 0,05 & $\mathrm{R}$ \\
\hline R $^{1}=$ Resistente & & &
\end{tabular}




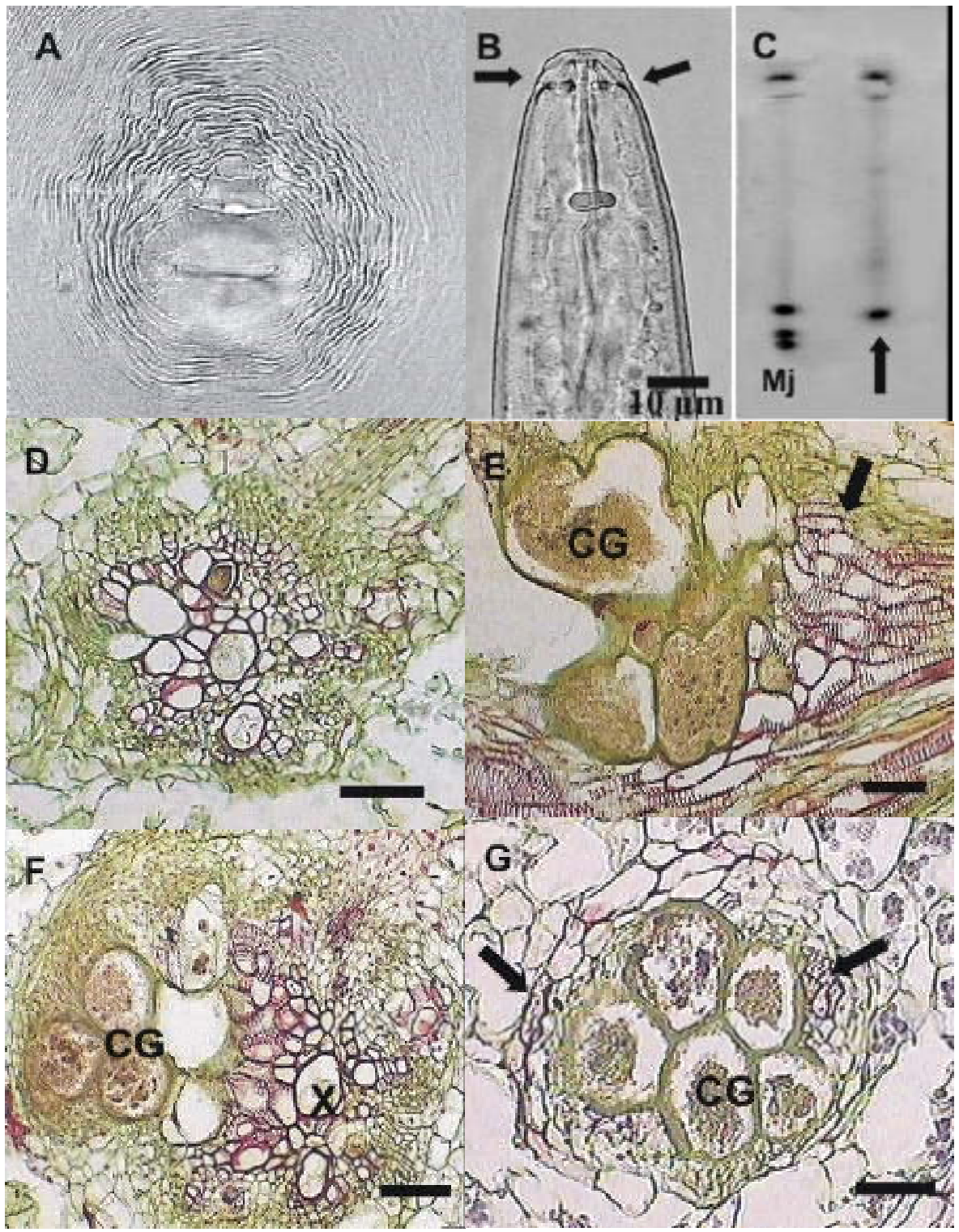

FIG. 1 - Características morfológicas e bioquímica da população de Meloidogyne incognita utilizada e reações em raízes de cultivares de batata-doce (Ipomoea batatas). A = Configuração perineal; B = região anterior de um macho, com detalhes da região labial; C = fenótipo de esterase. $\mathrm{D}=$ corte transversal de uma raiz sadia e $\mathrm{E}-\mathrm{G}=$ aspectos patológicos de tecidos infetados (Barras da escala para $\mathrm{D}-\mathrm{E}=1 \mu \mathrm{m})$.

utilizada na coloração do material, o xilema assumiu a cor avermelhada sendo visto como tecido predominante no cilindro central. Na Figura 1 E observa-se que um conjunto de células gigantes causou a deformação, desvio e obstrução de vasos do xilema. O desenvolvimento e a reprodução do nematóide dependem da formação de células gigantes e a má-formação dessas células está relacionada à resistência aos nematóides de galha (Taylor \& Sasser, 1978). Em seções transversais observa-se que a presença de células gigantes no cilindro central pode causar obstrução parcial do xilema (Figuras $1 \mathrm{~F}$ ) até a total supressão (Figura $1 \mathrm{G}$ ). Tais alterações anatômicas comprometem a eficácia do sistema vascular, quanto ao transporte de água e nutrientes, com reflexos no crescimento e produção das plantas.

\section{AGRADECIMENTOS}

À CAPES, pela concessão da bolsa. À UNESP/FCAV e UFPB/CFT, pela oportunidade de desenvolvimento do trabalho. A Tecnolanda Elane Rodrigues Pereira, pela contribuição na parte prática.

\section{REFERÊNCIAS BIBLIOGRÁFICAS}

BRIDGE, J. \& PAGE, S.L.M. Plant nematode pests of crops in Papua New Guinea. Journal of Plant Protection in the Tropics 1:99-109. 1984.

COOK, R. \& EVANS, K. Resistance and tolerance. In: Brown, R. H. $\&$ Kerry, B. R. (Eds.). Principles and practice of nematode control in 
crops. New York. Academic Press. 1987. pp.179-231.

COOLEN, W.A. \& D'HERD, C.J. A method for the quantitative extraction of nematodes from plant tissue. Ghent. State Agricultural Research Centre. 1972.

DAYKIN, M.E. \& HUSSEY, H.S. Staining and histopathological techniques in nematology. In: Barker, K.R., Carter, C.C. \& Sasser, J.N. (Eds.) An advanced treatise on Meloidogyne: methodology. Raleigh. North Carolina State University Graphics. 1985. pp.39-48.

EISENBACH, J.D. Diagnostic characters useful in the identification of the four most common species of root-knot nematodes (Meloidogyne spp.). In: Sasser, J.N. \& Carter, C.C. (Eds.) An advanced treatise on Meloidogyne; biology and control. Raleigh. North Carolina State University Graphics. 1985. pp.95-112.

ESBENSHADE, P.R. \& TRIANTAPHYLLOU, A.C. Isozyme phenotypes for identification of Meloidogyne species. Journal of Nematology 22:10-15. 1990.

GANDIN, C.L., THOMAZELLI, L.F., ALMEIDA, E.X. \& BOFF, P. Batata-doce, alimento energético. Agropecuária Catarinense 2122. 1988.

HUANG, S.P., MIRANDA, J.E.C. \& MALUF, W.R. Resistance to root-knot nematodes in brazilian sweet potato collection. Fitopatologia Brasileira 11:761-766. 1986.

JATALA, P. \& BRIDGE, J. Nematode parasites of root and tuber crops. In: Luc, M., Sikora, R.A. \& Bridge, J. (Eds.) Plant Parasitic
Nematodes in Subtropical and Tropical Agriculture. Wallingford. C A B International. 1990. pp.137-180.

KATAN, J. Solar heating (solarization) of soil for control of soilborne pests. Annual Review of Phytopathology 19:211-236. 1981.

LORDELLO, L.G. Nematóides das plantas cultivadas. 8 ed. São Paulo. Nobel. 1984.

MALUF, W.R., AZEVEDO, S.M. \& CAMPOS, V.P. Heritability of root knot nematode (Meloidogyne spp.) resistance in sweet potatoes. Journal Genetic and Breeding 50:161-165. 1996.

PEIXOTO, J.R., FERRAZ, F.M., SANTOS, L.C., DE ANGELIS, B. \& JULIATTI, F.C. Seleção de genótipos de batata-doce resistentes ao nematóide das galhas (Meloidogyne spp.). Fitopatologia Brasileira 23:51-53. 1998.

SILVA, V.F. Associações de características da batata-doce (Ipomoea batatas (L) Lamarck) com a sua resistência à "broca da raiz" Euscepes postfasciatus (Fairmaire). (Tese de Doutorado). Viçosa. Universidade Federal de Viçosa, 1991.

TAYLOR, A.L. \& NETSCHER, C. An improved technique for preparing perineal patterns of Meloidogyne spp. Nematologica 20: 268-269. 1974.

TAYLOR, A.L. \& SASSER, J.N. Biology, identification and control of root-knot nematodes (Meloidogyne species). Raleigh. North Carolina State University Graphics. 1978. 